\title{
The cognitive effects and decrements following concussion
}

This article was published in the following Dove Press journal:

Open Access Journal of Sports Medicine

II May 2010

Number of times this article has been viewed

\section{Tracey Covassin \\ Robert J Elbin}

Michigan State University, Department of Kinesiology, East Lansing, MI, USA
Correspondence:Tracey Covassin, Michigan State University, Department of Kinesiology, 105 IM Sport Circle, East Lansing, MI 48824, USA

Email covassin@msu.edu
Abstract: Sports-related concussion is an injury that continues to receive attention from both the popular media and sports medicine community. The many different symptom presentations and cognitive decrements that follow concussions, have made this injury difficult to detect and manage. Furthermore, concussed athletes should not always be entrusted to appropriately self-report their concussion symptoms; therefore the burden falls on the clinician and coach. Recent management recommendations call for using a multi-faceted approach to managing concussion, which consists of neurocognitive testing before (ie, baseline/preseason) and after injury. In addition age, sex, and previous history of concussion have been found to influence the risk and recovery from this injury.

Keywords: cognitive function, neurocognitive testing, concussion

\section{Cognitive effects and decrements following concussion}

Concussions remain a serious public health concern. The latest estimates from the Centers for Disease Control (CDC), indicates that sport-related concussions have increased to approximately 1.6 to 3.0 million per year. ${ }^{1}$ Moreover, recent studies report that the incidence of concussion at both the high school and collegiate level have been on the rise, as $8.9 \%$ of all high school and 5 to $18 \%$ of all collegiate athletic injuries are concussions. ${ }^{2,3}$ Specifically, the sports of football, soccer, and ice hockey have been found to have the highest incidence of concussion. ${ }^{2,3}$

The signs and symptoms that accompany concussion are not always detected by sports medicine professionals. Following a concussion, athletes may experience a wide variety of symptoms that include headache, dizziness, nausea, confusion, and other changes in cognitive function (eg, concentration, attention, and memory problems). However, sports medicine professionals often entrust athletes to self-disclose their symptoms, even though the burden falls on the clinician or coach. As a result concussions often go unreported as athletes have been found to: minimize the seriousness of their injury, fear being withheld from competition, fear being demoted, and lack the awareness and familiarity of the signs and symptoms of concussion. ${ }^{4}$ The lack of reporting of the symptoms of concussion has proven to be a significant obstacle for managing concussion and also determining when it is safe for the athlete to return to play. ${ }^{4}$

The recent implementation of neurocognitive testing, has provided a more objective means of detecting and measuring the acute and long-term changes in cognitive 
performance following a concussion. Neurocognitive testing batteries have also allowed researchers and sports medicine professionals to identify factors that influence cognitive outcomes. This review will provide an overview of the definition and pathophysiological basis of concussion, along with the empirically supported cognitive effects associated with this injury. In addition factors that have been found to influence the cognitive recovery from concussion will also be discussed.

\section{Defining a concussion}

There is currently no consensus on the exact definition of concussion. Many definitions have faltered in accurately describing the wide spectrum of symptoms and cognitive deficits that occur following this injury. Nonetheless, there are two primary definitions commonly used in concussion research. The Quality Standards Subcommittee of the American Association of Neurology (AAN), defines a concussion as, "an altered mental state that may or may not include loss of consciousness (LOC)". 5 This multi-disciplinary group agreed that the most prominent symptoms of concussions are amnesia and confusion, rather than LOC which does not accompany concussion as frequently as once thought. ${ }^{5} \mathrm{~A}$ second definition of concussion currently used today, was proposed by the Concussion in Sport (CIS) group. ${ }^{6}$ The CIS definition states that a concussion is a "complex pathophysiological process affecting the brain, induced by traumatic biomechanical forces". ${ }^{6}$ Supplementing this definition are five common features of concussion that incorporate clinical, pathological, and biomechanical constructs to further define and describe this injury. These defining features include: "1) concussion can be caused by direct impacts to the head, face, neck, or elsewhere on the body, with an 'impulsive' force transmitted toward the head; 2) concussion typically results in the rapid onset of short-lived impairment of neurological function that resolves spontaneously; 3) concussion may result in neuropathological changes, but the acute clinical symptoms largely reflect a functional disturbance rather than structural injury; 4) concussion results in a graded set of clinical syndromes that may or may not involve LOC; and 5) concussion is typically associated with grossly normal structural neuroimaging ". ${ }^{6}$

The variable nature of the signs and symptoms of concussion are presented differently in every concussed athlete, which has made defining this injury a very difficult task. The AAN and CIS definitions broadly account for the many different presentations of concussions, and provide a conservative approach to detecting concussion in sport. Moreover, these definitions help sports medicine professionals diagnose this injury which is a first step in managing concussion.

\section{Neurocognitive testing}

In recent years, computerized neurocognitive testing has played an increasing and important role in the evaluation and management of sports-related concussion. The CIS Group has endorsed neurocognitive testing as the "cornerstone" of concussion management. CIS believe these test batteries provide accurate reaction time, randomization of test trials, and automation of data collection and analysis. ${ }^{6}$ Given the large number of athletes that participate in collegiate and high school athletic programs, the use of computer-based neurocognitive test batteries are beneficial where paper-and-pencil tests have been deemed too timeconsuming and expensive. ${ }^{7}$ High school, collegiate, and professional athletes are currently utilizing: Immediate Post Concussion Assessment and Cognitive Testing (ImPACT), CogSport, Automated Neuropsychological Assessment Metrics (ANAM), or HeadMinder (Concussion Resolution Index: $\mathrm{CRI}$ ), for the assessment of sport-related concussions. For a review of the above mentioned computerized neurocognitive test batteries, see Schatz and Zillmer. ${ }^{7}$

Computerized neurocognitive test batteries may be best suited to identify neurocognitive impairments, track progress towards recovery, and assist in return-to-play decisions. This applies especially when post-concussive symptoms include a delayed onset of response time and increased decisionmaking time. ${ }^{7}$ Recent trends reflect not only the inclusion of baseline assessments in concussion management and assessment programs, but also utility of computerized assessment batteries. ${ }^{8}$ Baseline testing also has athletes serve as their own controls, which minimizes any confounding factors such as age, ${ }^{9}$ sex,${ }^{10}$ learning disability, ${ }^{11}$ education level, and/or hyperactivity disorders.

\section{Neurocognitive function and sports-related concussion}

The neurocognitive domains most susceptible to the acute effects of concussion, include attention and concentration, cognitive processing speed/efficiency, learning and memory, working memory, executive function and verbal fluency. ${ }^{12}$ The majority of research conducted on collegiate athletes suggests that cognitive impairments resolve within the first seven days of incurring a concussion. ${ }^{11,13-17}$ In a hallmark study, Barth et $a{ }^{18}$ conducted the first major study using preseason baseline neurocognitive measures on 2350 collegiate athletes from 
10 NCAA Division 1A football programs. All athletes who incurred a concussion during the season were reassessed on a paper and pencil neurocognitive test battery at 1,5 , and 10 days post-injury. Concussed athletes returned to baseline cognitive function within 5 days after injury. Similarly, McCrea et al ${ }^{13}$ examined concussed collegiate football players using a penciland-paper neurocognitive test battery. Concussed football players' cognitive function returned to baseline by 5 to 7 days post-injury. However, more than $10 \%$ of players were still exhibiting cognitive dysfunctions 7 days post-injury.

The general finding of $\mathrm{McCrea}$ et $\mathrm{al}^{13}$ provides an approximation for the recovery of cognitive function 5 to 7 days after concussion. However, the $10 \%$ of their sample still presenting with cognitive decrements at 7 days postconcussion, should not go unnoticed, as this brings about an important clinical point. The most recent position statements on sports-related concussion, call for a multifaceted and multi-disciplinary approach to managing this injury. ${ }^{12}$ Moreover, the symptomology of concussion has been found to be specific to each injured athlete and they should be treated and managed individually. This is rooted in the recent recommendations to discontinue the use of traditional concussion grading scales.

\section{Cumulative effects of concussion}

There seems to be a general consensus that a history of concussion has been found to influence the risk for subsequent concussive injury. ${ }^{19,20}$ Previous research has indicated that an athlete who incurs a concussion, is at a 3 to 6 times greater risk for sustaining a second concussion. ${ }^{11,20-22}$ Zemper $^{20}$ examined a sample of high school and collegiate football players during a two-year period. Players with a history of concussion were 5.8 times more likely to sustain a concussion than those without such a history. A similar study by Guskiewicz and colleagues, ${ }^{19}$ found collegiate athletes with a history of 3 or more concussions had a higher risk (3.4 times) of sustaining a subsequent concussion than those with two (2.8 times) or one (1.5 times) previous concussions. Collins et $\mathrm{al}^{23}$ also found support for an increased risk associated with history of concussion. Here, concussed high school athletes with 3 or more previous concussions were found to have a 9 times greater chance of exhibiting 3 or 4 on-field concussion symptoms. Specifically, athletes with a history of multiple concussions were more likely to experience on-field LOC (6.7 times), confusion (4.1), and anterograde amnesia (3.8 times) with subsequent concussion, compared to athletes without a history of multiple concussions.
More recently, McCrea and colleagues, ${ }^{24}$ examined the effects of a symptom-free waiting period with clinical outcomes (ie, neuropsychological testing) and risk of repeat concussion among high school and collegiate athletes. Results indicated that a symptom-free waiting period did not influence clinical outcomes or decrease the risk of repeat concussion. The researchers suggest that during the first 7 to 10 days following a concussion, athletes may be the most vulnerable to sustaining a second concussive injury.

Several researchers suggest a prior history of concussion is associated with a prolonged recovery following subsequent concussions. ${ }^{25-27}$ Concussed high school athletes with a history of 3 or more concussions presented more symptoms and a significantly lower memory performance at 2 days post-injury, compared to concussed athletes without a history of concussion. ${ }^{26} \mathrm{~A}$ recent study by Covassin and colleagues ${ }^{27}$ found that collegiate athletes with a history of 2 or more concussions, took longer to recover than athletes with no prior history of concussion. Specifically, athletes with no prior history of concussion recovered on all ImPACT cognitive domains, 5 days post-concussion. However, athletes with a history of 2 or more concussions were still impaired on verbal memory and reaction time 5 days post-injury.

Long-term neurocognitive impairments are rarely associated with a single concussion. However, research on the cumulative nature of concussion has been inconsistent in detecting any significant lingering cognitive effects after injury. Several researchers have suggested that the cumulative effects of multiple concussions can have long-term consequences. ${ }^{11,28-31}$ In addition, subconcussive blows to the head (ie, repeated hits to the head) may also have long-term consequences. ${ }^{30}$ The cumulative effects of repeated concussive and sub-concussive blows, have been studied in the sports of boxing, ${ }^{30}$ ice hockey, ${ }^{32}$ jockeys, ${ }^{33}$ and soccer players. ${ }^{34}$

The cumulative effects of multiple subconcussive blows to the head appear to be the primary cause of neurocognitive dysfunction in boxers. ${ }^{30}$ Jordan and colleagues ${ }^{30}$ examined the cognitive function in professional boxers by administering a battery of neurocognitive tests. These measured general intelligence, visual motor coordination, memory, language ability, construction skills, attention, and concentration and concept formation, cognitive stability and flexibility, and planning. Interestingly, boxers exhibited decreased performance on attention, concentration, memory, and visual motor coordination as sparring increased. Therefore, these authors concluded that repetitive subconcussive blows to the head may lead to cognitive deterioration of brain function. 
Researchers have suggested that there may be residual effects of concussion in collegiate athletes participating in soccer, lacrosse, ice hockey, and field hockey. ${ }^{31}$ Killam and colleagues ${ }^{31}$ administered the Repeatable Battery for the Assessment of Neuropsychological Status (RBANS), to investigate residual neurocognitive impairments of previously concussed collegiate athletes. Athletes were separated into three categories: recently concussed (ie, less than 2 years since last concussion), non-recently concussed (ie, more than 2 years since last concussion), or non-concussed. A fourth group consisted of a control group which was defined as non-concussed/non-athlete. Recently concussed athletes and non-concussed athletes demonstrated impairments in immediate and delayed memory when compared to non-concussed/non-athletes. Moreover, recently concussed athletes demonstrated impairments on immediate memory compared to non-recent concussed athletes. These results suggest that there may be a cumulative effect of concussion associated with immediate memory dysfunction in athletes.

Wall et $\mathrm{al}^{33}$ examined cognitive performance following a three-month recovery time from concussion in jockeys with a previous history of multiple concussions. Jockeys with multiple concussions exhibited worse neurocognitive performance than jockeys with no history of concussion. In addition, younger jockeys with a history of concussion demonstrated lower neurocognitive performance compared to older jockeys with a history of concussion. This finding suggests that having a history of concussion may place an athlete at risk for long-term cognitive decrements, with younger athletes having a higher vulnerability than older athletes.

While some studies support the premise that multiple concussions lead to long-term cognitive decline, other studies have not found results that support this association. For example Macciocchi and colleagues, ${ }^{35}$ found no cumulative effects for performance on Paced Auditory Serial Addition Task, Trail-Making Tests A and B and the Symbol Digit Test in collegiate football players who sustained 2 concussions greater than 2 weeks apart. In addition, research conducted on collegiate soccer players with a history of 2 or more concussions, found that they were no more likely to have impaired neurocognitive performance than those with no history of concussion. ${ }^{36}$

This disparity in the literature has prompted researchers to question the sensitivity of the measures (ie, neurocognitive test batteries), used to evaluate any long-term subtle changes in cognitive function following multiple concussions. ${ }^{37}$ However,
Bruce and Echemendia ${ }^{37}$ did not find any neurocognitive impairments in collegiate athletes who self-reported multiple concussions on either a traditional pencil and paper neuropsychological test or a computerized neurocognitive test. Furthermore, these two forms of neurocognitive assessment can measure vastly different neurocognitive constructs, such as free recall memory assessment versus forced-choice recognition memory paradigms used in computer forms of neurocognitive assessment. ${ }^{38}$ Moreover, researchers have yet to discover a commonly injured area in the brain for all concussions. Therefore, multiple tests should be employed. As a result, the assessment and management of sport-related concussions should be a multifaceted approach that consists of a clinical examination, completion of a self-reported symptom checklist, postural assessment, and neurocognitive testing. Future research on this topic is clearly warranted.

\section{Age differences in athletes}

Studies have shown that concussed high school athletes demonstrate longer recovery times with respect to neurocognitive performance than concussed collegiate

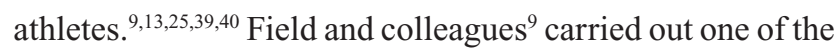
first studies to compare high school concussed football and soccer athletes, to collegiate concussed football and soccer athletes. Collegiate concussed players demonstrated memory impairments up to 24 hours, while high school concussed athletes demonstrated memory impairments up to 7 days post-injury. Similarly Lovell et $\mathrm{al}^{39}$ found that concussed high school athletes demonstrated memory verbal impairments 4 and 7 days post-injury when compared to matched controls. However, these initial studies did not track and test athletes past 7 days. Therefore, it is unclear how long high school concussed athletes demonstrate neurocognitive impairments.

More recent studies suggest high school athletes may take up to 14 days to recover from a concussion. McClincy et $\mathrm{al}^{41}$ administered a baseline ImPACT test and follow-up tests to concussed athletes (mean age $=16.11 \mathrm{yrs} \pm 1.89$ ) at 2, 7, and 14 days post-injury. Concussed athletes exhibited impairments on reaction time, verbal memory and visual memory 7 days post-injury. Concussed athletes continued to demonstrate impairments on verbal memory 14 days post-injury. These studies suggest that high school athletes demonstrate slower neurocognitive recovery after a sportsrelated concussion, compared to collegiate athletes.

There are several theories that have been proposed to account for these age-related differences in cognitive decrements following concussion. Specifically, decreased myelination, larger subarachnoid space in the cranium 
(eg, allowing more room for brain movement), and thinner cranium bones, may predispose younger athletes to more adverse effects from concussion. ${ }^{42-45}$ In addition, the immature brain has also been shown to be up to 60 times more sensitive to glutamate-mediated $N$-methyl-D-aspartate (NMDA), a prevalent neurotransmitter released in the brain following concussion. ${ }^{46,47}$ It appears that age is a factor that needs to be considered when managing sports-related concussion, as younger athletes are more at risk for the severe consequences following a second concussion before the first one completely resolves.

\section{Sex differences in athletes}

While the majority of concussion research has been conducted on male athletes, one cannot ignore the fact that female sport participation has steadily increased over the past decade. Over 178,000 females are currently participating on NCAA teams ${ }^{48}$ and approximately 3 million females playing organized high school sports. ${ }^{49}$ Although severity of concussion has been reported to be higher among male athletes, ${ }^{50}$ female athletes have been found to be at a greater inherent risk for concussions in basketball and soccer. ${ }^{51}$ To date, the majority of literature on concussions and neurocognitive function has concentrated on football, men's ice hockey, boxing, and soccer players. Moreover, research indicates that male and female athletes' brain function varies. ${ }^{52}$ Therefore, it is important to determine if sexes exhibit differences in cognitive function following concussion, potentially leading to different recovery patterns.

Very few researchers have examined sex differences and concussion outcomes. Broshek and colleagues ${ }^{53}$ examined high school and collegiate athletes cognitive recovery following a sports-related concussion. Female athletes demonstrated slower simple and complex reaction times following a concussion compared to baseline scores and 1.7 times more impairments on these reaction time measures compared to male athletes. Similarly, Colvin et $\mathrm{al}^{54}$ found female soccer players had slower reaction time scores compared to male soccer players. In another study by Covassin et $\mathrm{al}^{55}$ concussed female collegiate athletes performed significantly worse than concussed male collegiate athletes on visual memory scores. These findings are among the first to suggest that sex differences may exist following sports-related concussion.

Sex differences in cognitive function following a concussion may be due to hormonal differences, neuroanatomical differences, or cerebrovascular organization. ${ }^{42,56-59}$ Researchers have found that females have greater neurophil and decreased cortical neuronal densities compared to males, which may play a role in memory and information processing. ${ }^{57}$ In addition, females also have a greater basal rate of glucose metabolism ${ }^{60}$ and cerebral blood flow ${ }^{58}$ compared to males, which may affect the changes in the neurometabolic cascade that follows concussive injury. ${ }^{61}$ In addition to these potential explanatory factors, men and women are likely to have different cognitive strengths and weaknesses that should be accounted for when interpreting cognitive performance following concussion. For instance, women perform better on verbal memory, while men perform better on visual spatial skills. ${ }^{62,63}$

\section{Summary}

Sport-related concussion is a puzzling injury for both the athlete and the sports medicine professional. Future efforts should focus on educating athletes, coaches, and parents on the signs and symptoms of concussions and the dangers associated with withholding these symptoms from sports medicine professionals. In addition, sports medicine professionals should seek credible sources of information on concussion and develop a multi-faceted and multi-disciplinary approach to managing this injury. The aforementioned factors that influence the risk and recovery from sports-related concussion should also be considered when diagnosing and making return-to-play decisions. A multi-faceted approach to managing concussion and utilizing a multi-disciplinary team is the best practice to ensure that concussed athletes are managed appropriately and are safe to return to competition.

\section{Disclosures}

The authors report no conflicts of interest.

\section{References}

1. Centers for Disease Control and Prevention (CDC). Sports-related injuries among high school athletes in the United States. MMWR Morb Mortal Wkly Rep. 2006;55.

2. Hootman J, Dick R, Agel J. Epidemiology of collegiate injuries for 15 sports: Summary and recommendaitons for injury precention initiatives. J Athl Train. 2007;42:311-319.

3. Gessel LM, Fields SK, Collins CL, Dick RW, Comstock RD. Concussions among united states high school and collegiate athletes. J Athl Train 2007;42:495-503

4. McCrea M, Hammeke T, Olsen G, Leo P, Guskiewicz KM. Unreported concussion in high school football players: implications for prevention. Clin J Sport Med. 2004;14:13-17.

5. American Academy of Neurology. Practice parameter: the management of concussion in sports (summary statement). Report of the Quality Standards Subcommittee. Neurology. 1997;48:581-585.

6. Aubry M, Cantu R, Dvorak J, et al. Summary and agreement statement of the 1st International Symposium on Concussion in Sport, Vienna 2001. Clin J Sport Med. 2002;12:6-11.

7. Schatz P, Zillmer EA. Computer-based assessment of sports-related concussion. Appl Neuropsychol. 2003;10:42-47. 
8. McKeever CK, Schatz P. Current issues in the identification, assessment, and management of concussions in sports-related injuries. Appl Neuropsychol. 2003;10:4-11.

9. Field M, Collins MW, Lovell MR, Maroon J. Does age play a role in recovery form sports-related concussion? A comparison of high school and collegiate athletes. J Pediatr. 2003;142:546-553.

10. Covassin T, Schatz P, Swanik B. Sex differences in neuropsychological function and post-concussion symptoms of concussed collegiate athletes. Neurosurgery. 2007;61:345-351.

11. Collins MW, Grindel SH, Lovell MR, et al. Relationship between concussion and neuropsychological performance in college football players. JAMA. 1999;282:964-970.

12. Guskiewicz KM, Bruce SL, Cantu R, et al. National Athletic Trainers' Association Position Statement: Management of sports-related concussion. J Athl Train. 2004;39:280-297.

13. McCrea M, Guskiewicz KM, Marshall SW, et al. Acute effects and recovery time following concussion in collegiate football players: The NCAA concussion study. JAMA. 2003;290:2556-2563.

14. Macciocchi SN, Barth JT, Alves W, Rimel RW, Jane JA. Neuropsychological functioning and recovery after mild head injury in collegiate athletes. Neurosurgery. 1996;39:510-514.

15. Guskiewicz K, Ross S, Marshall S. Postural stability and neuropsychological deficits after concussion in collegiate athletes.J Athl Train. 2001;36:263-273.

16. Echemendia R, Putukian M, Mackin R, Julian L, Shoss N. Neuropsychological test performance prior to and following sports-related mild traumatic brain injury. Clin Sports Med. 2001;11:23-31.

17. Bleigerb J, Cernich A, Cameron K, et al. Duration of cognitive impairment after sports concussion. Neurosurgery. 2004;54:1073-1080.

18. Barth JT, Alves W, Ryan T, et al. Mild Head Injury. In Levin H, Eisenberg H, Benton A, eds. Mild Head Injury in Sports: Neuropsychological Sequelae and Recovery of Function. New York, NY: Oxford University Press; 1989.

19. Guskiewicz KM, McCrea M, Marshall SW, et al. Cumulative effects associated with recurrent concussion in collegiate football players: the NCAA Concussion Study. JAMA. 2003;290:2549-2555.

20. Zemper ED. Two-year prospective study of relative risk of a second cerebral concussion. Am J Phys Med Rehabil. 2003;82:653-659.

21. Guskiewicz KM, Weaver NL, Padua DA, Garrett WE Jr. Epidemiology of concussion in collegiate and high school football players. Am J Sports Med. 2000;28:643-650.

22. Gerberich SG, Priest JD, Boen JR, Straub CP, Maxwell RE. Concussion incidences and severity in secondary school varsity football players. Am J Public Health. 1983;73:1370-1375.

23. Collins MW, Lovell MR, Iverson GL, Cantu R, Maroon J, Field M. Cumulative effects of concussion in high school athletes. Neurosurgery. 2002;51:1175-1179.

24. McCrea M, Guskiewicz K, Randolph C, et al. Effects of a symptom-free wating period on clinical outcome and risk of reinjury after sport-related concussion. Neurosurgery. 2009;65:876-883.

25. Moser RS, Schatz P, Jordan BD. Prolonged effects of concussion in high school athletes. Neurosurgery. 2005;57:300-306.

26. Iverson GL, Gaetz M, Lovell MR, Collins MW. Cumulative effects of concussion in amateur athletes. Brain Inj. 2004;18:433-443.

27. Covassin T, Stearne D, Elbin R. Concussion history and postconcussion neurocognitive performance and symptoms in collegiate athletes. $J$ Athl Train. 2008;43:119-124.

28. Bream H. Postconcussion syndrome: a case study. Athl Ther Today. 1996;1:7-10.

29. Gronwall D, Wrightson P. Delayed recovery of intellectual function following minor head injury. Lancet. 1974;2:605-609

30. Jordan B, Matser E, Zimmerman R, Zazula T. Sparring and cognitive function in professional boxers. Phys Sportsmed. 1996;24:87-98.

31. Killam C, Cautin RL, Santucci AC. Assessing the enduring residual neuropsychological effects of head trauma in college athletes who participate in contact sports. Arch Clin Neuropsychol. 2005;20: 599-611.
32. Tegner Y, Lorentzon R. Concussion among Swedish elite ice hockey players. Br J Sports Med. 1996;30:251-255.

33. Wall SE, Williams WH, Cartwright-Hatton S, et al. Neuropsychological dysfunction following repeat concussions in jockeys. J Neurol Neurosurg Psychiatry. 2006;77:518-520.

34. Matser JT, Kessels AGH, Lezak MD, Troost J. A dose-response relation of headers and concussions with cognitive impairment in professional soccer players. J Clin Exp Neuropsychol. 2001;23:770-774.

35. Macciocchi S, Barth J, Littelfield L, Cantu R. Multiple concussions and neuropsychological functioning in collegiate football players. J Athl Train. 2001;36:303-307.

36. Guskiewicz KM, Marshall SW, Broglio S, Cantu R, Kirkendall DT. No evidence of impaired neurocognitive performance in collegiate soccer players. Am J Sports Med. 2002;30:157-162.

37. Bruce J, Echemendia R. History of multiple self-reported concussions is not associated with reduced cognitive abilites. Neurosurgery. 2009;64:100-106

38. Bruce J, Echemendía RJ. History of multiple self-reported concussions is not associated with reduced cognitive abilities. Neurosurgery. 2009; 64:100-106.

39. Lovell MR, Collins MW, Iverson GL, Field M, Maroon J, Cantu R. Recovery from mild concussion in high school athletes. J Neurosurg. 2003;98:296-301.

40. Sim A, Terryberry-Spohr L, Wilson KR. Prolonged recovery of memory functioning after mild traumatic brain injury in adolescent athletes. J Neurosurg. 2008;108:511-516.

41. McClincy MP, Lovell MR, Pardini J, Collins MW, Spore MK. Recovery from sports concussion in high school and collegiate athletes. Brain Inj. 2006;20:33-39.

42. Tierney R, Higgins M, Caswell S, et al. Sex differences in head acceleration during heading while wearing soccer headgear. J Athl Train. 2008;43:578-584.

43. Baur R, Fritz H. Pathophysiology of traumatic injury in the developing brain: An introduction and short update. Exp Toxicol Pathol. 2004;56:65-73.

44. Gefen A, Gefen N, Zhu Q, Raghupathi R, Margulies S. Age-dependent changes in material properties of the brain and braincase of the rat. J Neurotrauma. 2003;20:1163-1177.

45. Prins M, Hovda DA. Developing experimental models to address traumatic brain injury in children. J Neurotrauma. 2003;20:123-137.

46. McDonald JW, Johnston MV. Physiological pathophysiological roles of excitatory amino acids during central nervous system development. Brain Res Rev. 1990;15:41-70.

47. McDonald JW, Silverstein FS, Johnston MV. Neurotoxicity of $\mathrm{N}$-methyl-D-aspartate is markedly enhanced in developing rat central nervous system. Brain Res. 1988;459:200-203.

48. DeHaas DM. 1981-82-2007-08 NCAA Sports Sponsorship and Participation Rates Report: National Collegiate Athletic Association; 2009.

49. NFHSA. Participation in high school sports increases again; confirms NFHS commitment to stronger leadership. http:/www.nfhs.org/ web/2006/09/participation_in_high_school_sports_increases_again_ confirms_nf.aspx. Accessed February 28, 2007.

50. Barnes B, Cooper L, Kirkendall D, McDermott P, Jordan B, Garrett W. Concussion history in elite male and female soccer players. Am J Sports Med. 1998;26:433-438.

51. Covassin T, Swanik C, Sachs M. Sex differences and the incidence of concussions among collegiate athletes. J Athl Train. 2003;38:238-244.

52. Murphy D, DeCarli C, McIntosh A. Sex differences in human brain morphometry and metabolism an in vivo quantitative magnetic resonance imaging and positron emission tomography study on the effect of aging. Arch Gen Psychiatry. 1996;53:585-594.

53. Broshek DK, Kaushik T, Freeman JR, Erlanger D, Webbe F, Barth JT. Sex differences in outcome following sports-related concussion. J Neurosurg. 2005;102:856-863.

54. Colvin A, Mullen J, Lovell M, West R, M C, Groh M. The role of concussion history and gender in recovery from soccer-related concussion. Am J Sports Med. 2009;37:1699-704. 
55. Covassin T, Schatz P, Swanik B. Sex differences in neuropsychological function and post-concussion symptoms of concussed collegiate athletes. Neurosurgery. 2007;61:345-351.

56. Tierney RT, Sitler MR, Swanik B, Swanik K, Higgins M, Torg J. Gender differences in head-neck segment dynamic stabilization during head acceleration. Med Sci Sports Exerc. 2005;37:272-279.

57. de Courten-Myers GM. The human cerebral cortex: gender differences in structure and function. J Neuropathol Exp Neurol. 1999;58:217-226.

58. Esposito G, Van Horn JD, Weinberger DR, Berman KF. Gender differences with cerebral blood flow as a function of cognitive state with PET. Journal of Neurologic Medicine. 1996;37:559-564.

59. Emerson C, Headrick J, Vink R. Estrogen improves biochemical and neurologic outcome following traumatic brain injury in male rats, but not females. Brain Res. 1993;608:95-100.
60. Andreason P, Zametkin A, Guo A, Baldwin P, Cohen R. Gender-related differences in regional cerebral glucose metabolism in normal volunteers. Psychiatry Res. 1994;51:175-183.

61. Hovda D, Lee SM, Smith ML. The neurochemical and metabolic cascade following brain injury: Moving from animal models to man. J Neurotrauma. 1995;12:903-906.

62. Kimura D, Clarke P. Women's advantage on verbal memory is not restricted to concrete words. Psychol Rep. 2002;91:1137-1142.

63. Powell JW, Barber-Foss KD. Traumatic brain injury in high school athletes. JAMA. 1999;282:958-963.

Open Access Journal of Sports Medicine

\section{Publish your work in this journal}

Open Access Journal of Sports Medicine is an international, peer-reviewed, open access journal publishing original research, reports, reviews and commentaries on all areas of sports medicine. The manuscript management system is completely online and includes a very quick and fair peer-review system.

\section{Dovepress}

Visit http://www.dovepress.com/testimonials.php to read real quotes from published authors. 